\title{
The effect of dexmedetomidine versus propofol in traumatic brain injury: evaluation of some hemodynamic and intracranial pressure changes
}

\author{
Mohammed Khallaf ${ }^{1 *}$, Ahmed Mostafa Thabet ${ }^{2}$, Mahmoud Ali $^{2}$, Essam Sharkawy ${ }^{2}$ and Sherif Abdel-rehim ${ }^{2}$
}

\begin{abstract}
Background: Cerebral edema and increased intracranial pressure are of the major consequences of traumatic brain injury that affects the outcome. The aim of this study is to assess the efficacy of dexmedetomidine as an adjunct to conventional sedative therapy (propofol) compared to conventional sedative therapy alone in patients with traumatic brain injury, as regards its effects on hemodynamics and intracranial pressure.

Methods: This prospective randomized controlled clinical trial with 60 agitated and restless traumatic brain-injured patients was performed between May 2013 and May 2017. Patients who required mechanical ventilation, Glasgow coma scale $(\mathrm{GCS})<8$, or hemodynamically instable were excluded. Patients were randomized into three equal groups: dexmedetomidine was infused in a dose of $0.5 \mu \mathrm{g} / \mathrm{kg} / \mathrm{h}$ for $48 \mathrm{~h}$ in the first group, propofol $1 \%$ was infused in a dose of $4 \mathrm{mg} / \mathrm{kg} / \mathrm{h}$ for $48 \mathrm{~h}$ in the second group, and dexmedetomidine was infused in a dose of $0.2 \mu \mathrm{g} / \mathrm{kg} / \mathrm{h}$ and propofol was infused in a dose of $2 \mathrm{mg} / \mathrm{kg} / \mathrm{h}$ for $48 \mathrm{~h}$ in the third group. ICP and CPP excursions and complications were assessed in the first $48 \mathrm{~h}$.

Results: The number of ICP and CPP excursions per day was not significantly different between the three groups. Tachycardia, bradycardia, and hypertension in the three groups were statistically insignificant. As regards hypotension, there was a statistically significant difference between the three studied groups.

Conclusion: Dexmedetomidine or its combination with propofol is as effective as propofol alone in TBl; all alternatives are equal as regards the degree of sedation, effect on intracranial pressure, and cerebral perfusion pressure. The incidence of complications does not vary greatly between all groups.
\end{abstract}

Trial registration: 17200257 registered 5/2013

Keywords: Traumatic brain injuries, Sedation, Dexmedetomidine, Propofol

\section{Introduction}

\section{Main text}

TBI is a significant public health problem worldwide and is predicted to surpass many diseases as a major cause of death and disability. Cerebral edema and associated increased intracranial pressure are the major immediate consequences of TBI that contribute to most early deaths. An increase in intracranial pressure (ICP) may impede cerebral blood flow $(\mathrm{CBF})$ and lead to cerebral ischemia

\footnotetext{
* Correspondence: khallaf_1973@yahoo.com

${ }^{1}$ Department of Neurosurgery, Assiut University Hospital, Assiut, Egypt Full list of author information is available at the end of the article
}

[1], and its degree and duration are associated with outcome after TBI [2-4]. So, the primary aim of the intensive care management of TBI is to prevent and treat secondary ischemic injury. Prevention and control of increased ICP and maintenance of cerebral perfusion pressure (CPP) are fundamental therapeutic goals after TBI [1]. Several different classes of drugs are used as sedatives, but there is limited evidence available to guide the choice of specific sedative agents in TBI [5].

Dexmedetomidine is a highly selective $\alpha 2$-adrenergic agonist that possesses sedative-, anxiolytic-, and analgesicsparing properties. The mechanism beyond the reduction 

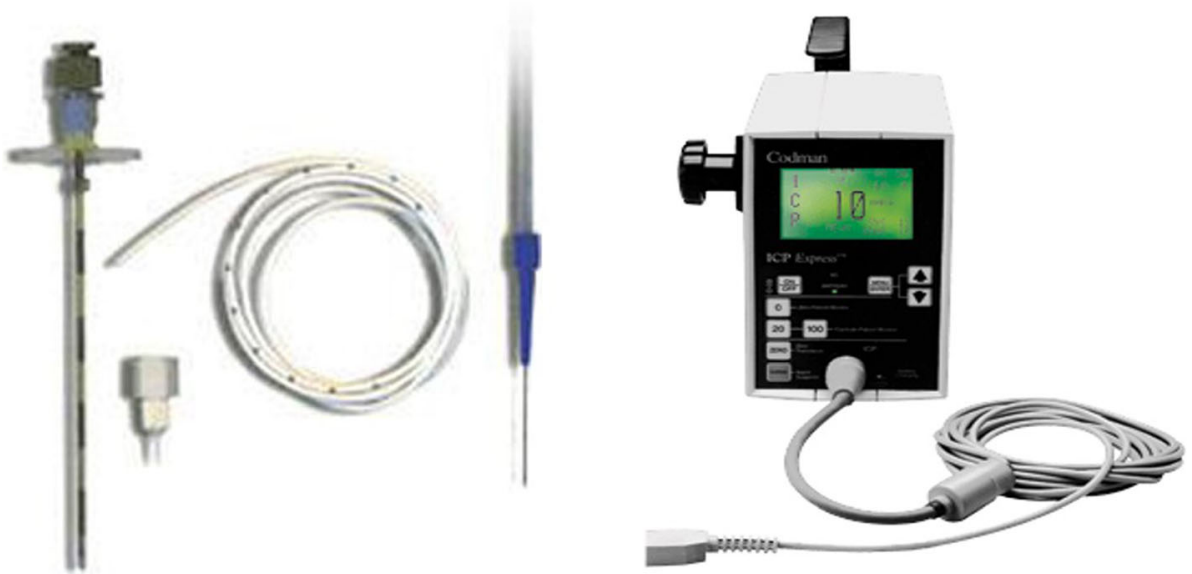

Fig. 1 Codman micro sensor ICP monitor and catheter

of ICP in trauma patients may be due to arterial vasoconstriction induced by $\alpha 2$ agonist activity which in turn leads to a decrease in the cerebral blood volume $[2,6]$. It provides excellent sedation without respiratory depression, ease of arousability, and short-acting effects, has sympatholytic properties, and need not be stopped during weaning the patient from mechanical ventilation or for neurological assessment. It suits as an ideal sedative agent for patients with TBI [7].

The efficacy of dexmedetomidine for sedation in intubated ICU patients is well established; however, its use in patients with traumatic brain injury (TBI) has not been comprehensively described. The aim of this study is to assess the efficacy of dexmedetomidine as an adjunct to conventional sedative therapy (propofol) compared to conventional sedative therapy alone in patients with traumatic brain injury, as regards its effects on hemodynamics and intracranial pressure.

\section{Patients and methods}

This prospective randomized controlled clinical trial included 60 head-injured patients and was performed in the
Trauma Intensive Care Units, Department of Anesthesia, and Intensive Care and Department of Neurosurgery, Assiut University Hospital (single Tertiary Hospital) between May 2013 and May 2017.

Inclusion criteria for the patients in this study were as follows: ASA I-III, patient between 18 and 80 years, Glasgow coma scale (GCS) $\geq 8$, agitated and restless patients in need for sedation and close follow-up, diagnosis of TBI by CT or abnormal posturing, and placement of an intracranial pressure monitor at the discretion of the neurosurgical staff as a part of the standard of care. Exclusion criteria were as follows: patients who need mechanical ventilation on admission, AV block with $\mathrm{HR}$ $<45 /$ min, and severe preadmission hemodynamic instability. For each patient, the following demographic data were collected from the trauma registry: sex, age, weight $(\mathrm{kg})$, height $(\mathrm{cm})$, BMI, Trauma Severity Score, and GCS on admission.

Allocated patients were randomized, using a programgenerated random number table, into three groups; allocation concealment was done using opaque well-sealed envelopes which were opened sequentially for each allocated

Table 1 Patient characteristics

\begin{tabular}{|c|c|c|c|c|}
\hline Parameter & Propofol group $(n=20)$ & DEX group $(n=20)$ & Mixed group $(n=20)$ & $p$ value \\
\hline Age (years) & $38.7 \pm 11$ & $39.3 \pm 8.5$ & $39.3 \pm 10.2$ & 0.972 \\
\hline Gender (male/female) & $16 / 4$ & $19 / 1$ & $18 / 2$ & 0.322 \\
\hline Weight (kg) & $85.4 \pm 10.7$ & $85.2 \pm 13.3$ & $84 \pm 10.9$ & 0.920 \\
\hline Height (centimeters) & $171.7 \pm 8.4$ & $173.6 \pm 8.6$ & $171.5 \pm 9$ & 0.688 \\
\hline BMl & $30 \pm 3.3$ & $29.6 \pm 3.2$ & $30.1 \pm 3.1$ & 0.890 \\
\hline Trauma Severity Score & $30.95 \pm 5.7$ & $28.95 \pm 4.2$ & $30.85 \pm 6.4$ & 0.437 \\
\hline $\begin{array}{l}\text { Time relapsed before } \\
\text { ICU admission (hours) }\end{array}$ & $4.3 \pm 1.2$ & $4.2 \pm 1.1$ & $3.8 \pm 0.9$ & 0.360 \\
\hline $\begin{array}{l}\text { GCS on admission } \\
\text { - Mild; GCS }>12 \\
\text { - Moderate; GCS }=8-11\end{array}$ & $\begin{array}{l}14 \\
6\end{array}$ & $\begin{array}{l}16 \\
4\end{array}$ & $\begin{array}{l}15 \\
5\end{array}$ & 0.766 \\
\hline
\end{tabular}




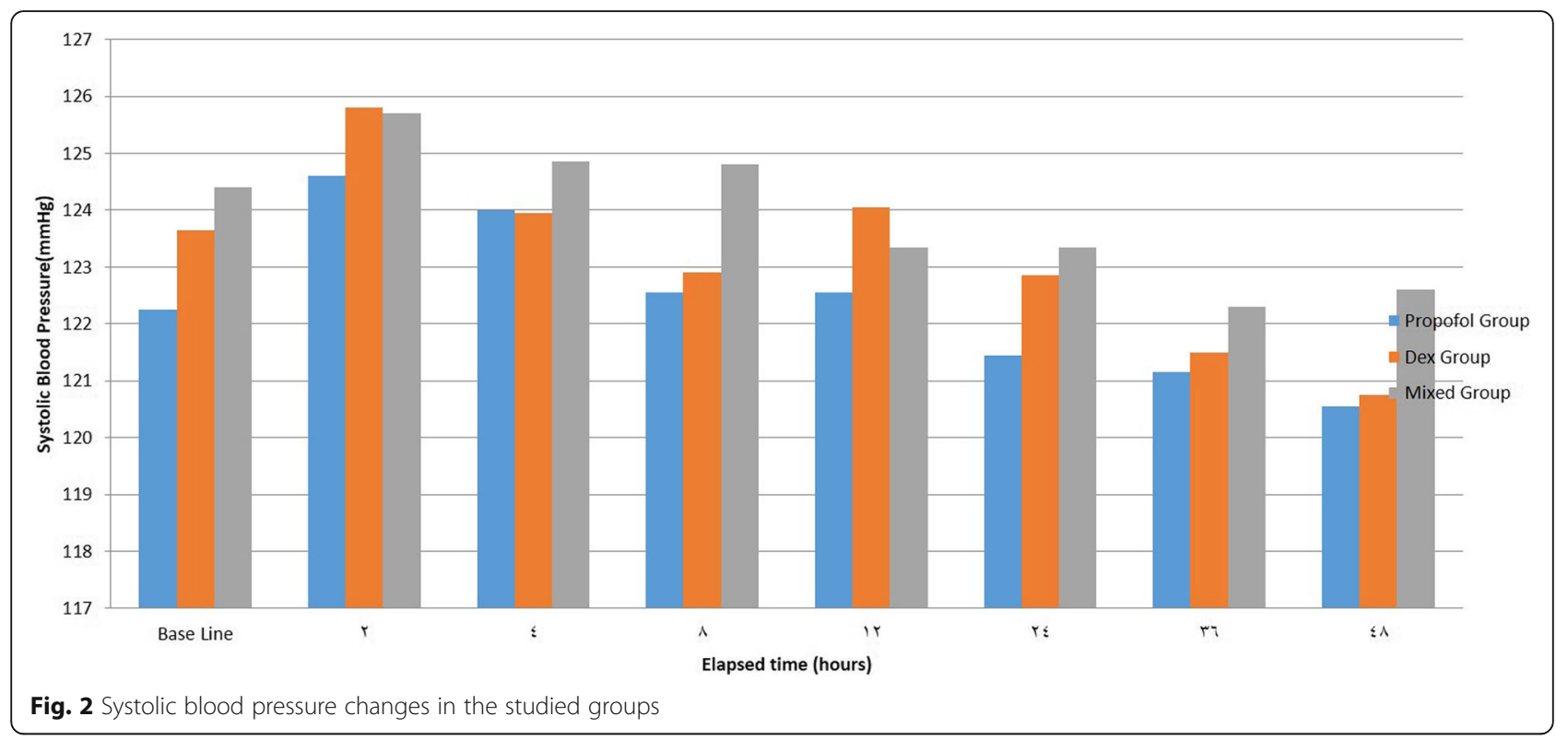

patient. Groups are based on the type of sedation used in the ICU; patients were randomized into three groups; dexmedetomidine group $(n=20)$ : dexmedetomidine (Prece$\operatorname{dex}^{\circ}$ Dexmedetomidine $\mathrm{HCl}$ vial, HOSPIRA, INC) was infused in a loading dose of $1 \mu \mathrm{k} / \mathrm{kg}$ followed by I.V infusion of $0.4-1 \mu \mathrm{k} / \mathrm{kg} / \mathrm{h}$. The dexmedetomidine is supplied in a 2-ml vial of $100 \mu \mathrm{g} / \mathrm{ml}$; each vial was diluted in $48 \mathrm{~mL}$ of normal saline in a syringe pump to yield a final concentration of $4 \mu \mathrm{g} / \mathrm{ml}$ and infused for $48 \mathrm{~h}$.

Propofol group $(n=20)$ : propofol 1\% (Fresenius Kabi $\mathrm{AB}$ ) in 20-ml ampoule was administrated as a loading dose of $1 \mathrm{mg} / \mathrm{kg}$ followed by maintenance dose of $1.5-4.5$ $\mathrm{mg} / \mathrm{kg} / \mathrm{h}$ titrated to the desired effect. Propofol was infused in a 50-ml syringe pump for $48 \mathrm{~h}$. Dexmedetomidine + propofol group $(n=20)$ : dexmedetomidine were infused in a dose of $0.2 \mu \mathrm{g} / \mathrm{kg} / \mathrm{h}$ and propofol were infused in a dose of $2 \mathrm{mg} / \mathrm{kg} / \mathrm{h}$ for $48 \mathrm{~h}$. Sedative agents were titrated to reach a goal of $\mathrm{ICP}<20 \mathrm{mmHg}$ and $\mathrm{CPP}>60 \mathrm{mmHg}$ with calm patients (controlling agitation, restlessness, and anxiety). After starting the infusion, strict and vigil monitoring of hemodynamic and respiratory parameters at regular intervals of $2 \mathrm{~h}$ for $48 \mathrm{~h}$ was done. Patients fulfilling the inclusion criteria were admitted to the Trauma Intensive Care Unit and were treated according to our standard protocol for treatment of TBI.

At ICU, to describe physiological changes, baseline parameters were observed and recorded, which included heart rate (HR), systolic, diastolic, and mean arterial blood pressures, respiratory rate, and pulse oximetry (SpO2). Intracranial pressure (ICP) was monitored by an intraparenchymal

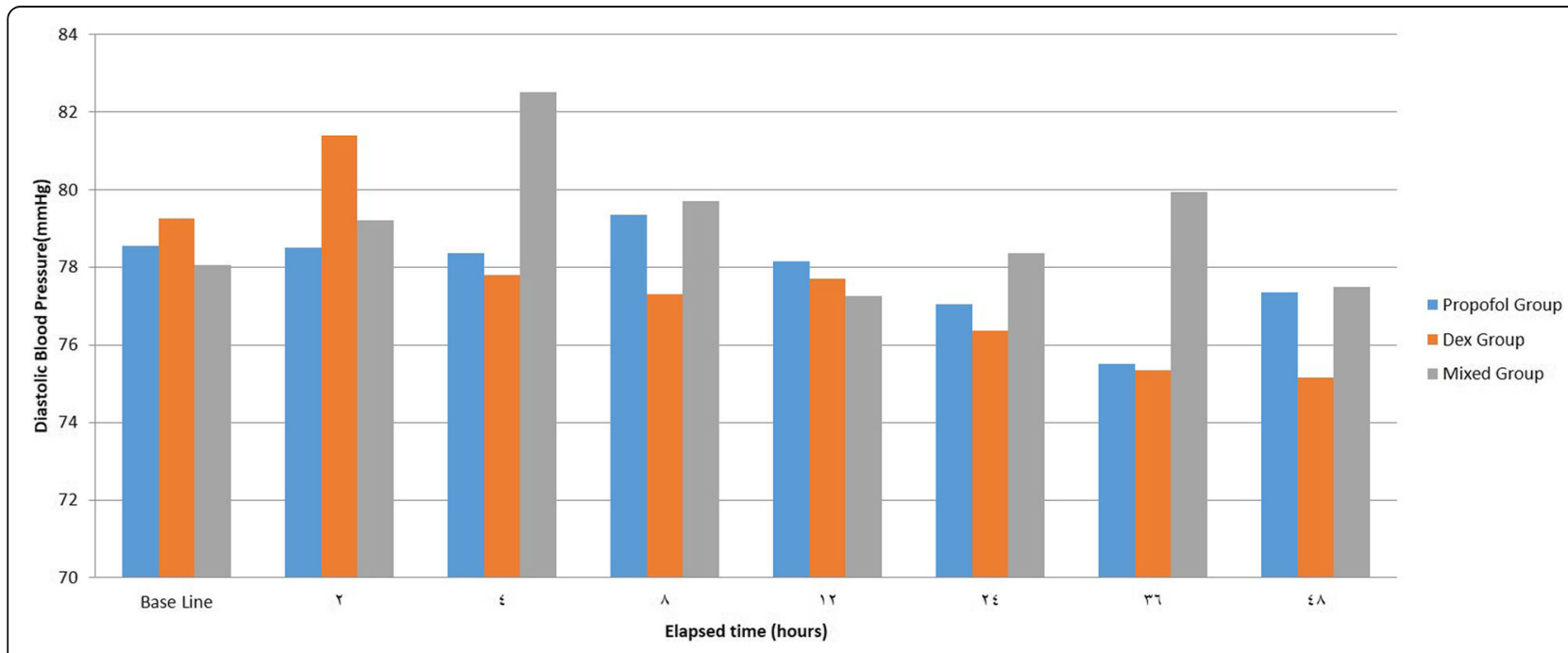

Fig. 3 Diastolic blood pressure changes in the studied groups 


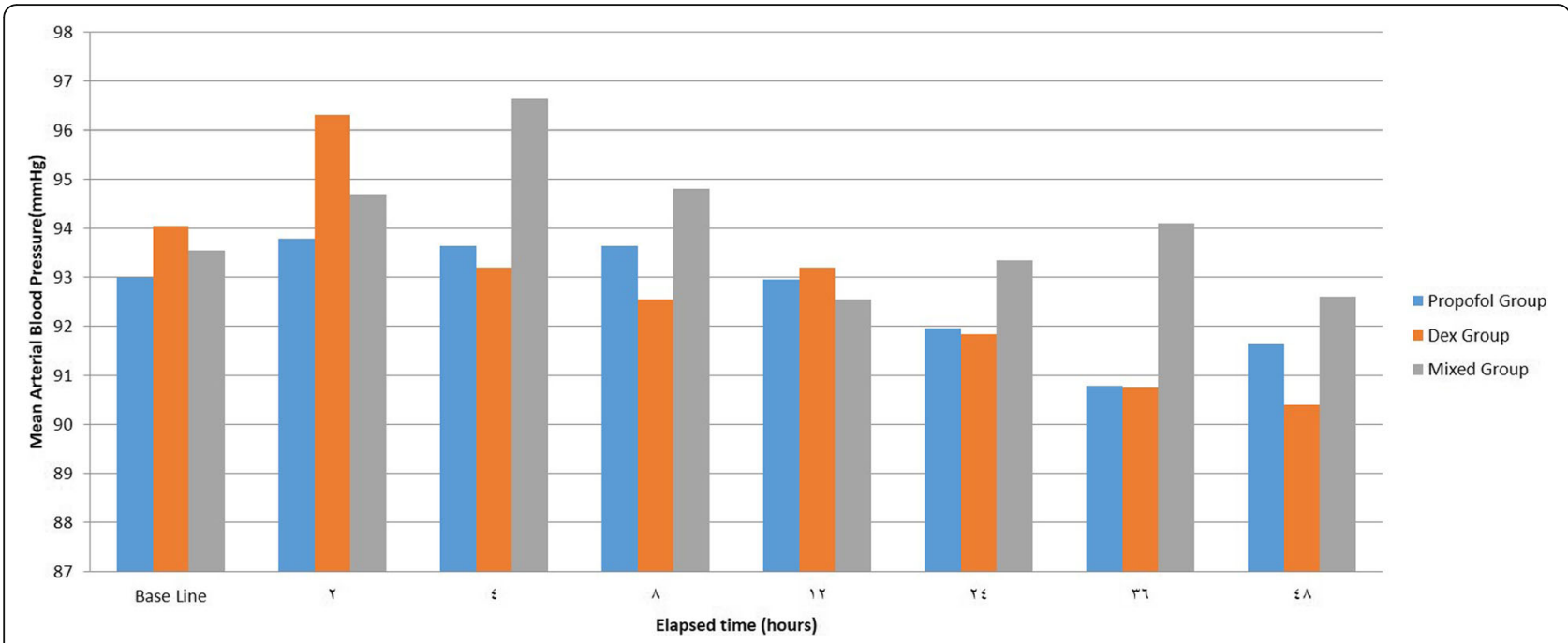

Fig. 4 Mean arterial blood pressure changes in the studied groups

Table 2 Blood pressure changes in the studied groups

\begin{tabular}{|c|c|c|c|c|}
\hline & Propofol group $(n=20)$ & DEX group $(n=20)$ & Mixed group $(n=20)$ & $p$ value \\
\hline \multicolumn{5}{|c|}{ Systolic blood pressure } \\
\hline Baseline & $122.25 \pm 3.57$ & $123.65 \pm 5.11$ & $124.4 \pm 4.74$ & 0.319 \\
\hline After $2 \mathrm{~h}$ & $124.6 \pm 3.83$ & $125.8 \pm 4.7$ & $125.7 \pm 5.01$ & 0.652 \\
\hline After $4 \mathrm{~h}$ & $124 \pm 4.47$ & $123.95 \pm 5.38$ & $124.85 \pm 6$ & 0.835 \\
\hline After $8 \mathrm{~h}$ & $122.55 \pm 6.3$ & $122.9 \pm 7.72$ & $124.8 \pm 6.91$ & 0.553 \\
\hline After $12 \mathrm{~h}$ & $122.55 \pm 3.82$ & $124.05 \pm 4.45$ & $123.35 \pm 6.7$ & 0.655 \\
\hline After $24 \mathrm{~h}$ & $121.45 \pm 6.97$ & $122.85 \pm 5.14$ & $123.35 \pm 7.8$ & 0.654 \\
\hline After $36 \mathrm{~h}$ & $121.15 \pm 6.56$ & $121.5 \pm 7.04$ & $122.3 \pm 9.66$ & 0.894 \\
\hline After $48 \mathrm{~h}$ & $120.55 \pm 8.29$ & $120.75 \pm 8.74$ & $122.6 \pm 10.48$ & 0.741 \\
\hline \multicolumn{5}{|c|}{ Diastolic blood pressure } \\
\hline Baseline & $78.55 \pm 6.86$ & $79.25 \pm 8.55$ & $78.05 \pm 5.92$ & 0.869 \\
\hline After $2 \mathrm{~h}$ & $78.5 \pm 5.38$ & $81.4 \pm 6.08$ & $79.2 \pm 6.95$ & 0.308 \\
\hline After $4 \mathrm{~h}$ & $78.35 \pm 7.24$ & $77.8 \pm 8.39$ & $82.5 \pm 7.72$ & 0.123 \\
\hline After $8 \mathrm{~h}$ & $79.35 \pm 6.35$ & $77.3 \pm 7.98$ & $79.7 \pm 10.59$ & 0.630 \\
\hline After $12 \mathrm{~h}$ & $78.15 \pm 6.85$ & $77.7 \pm 5.8$ & $77.25 \pm 8.11$ & 0.920 \\
\hline After $24 \mathrm{~h}$ & $77.05 \pm 7.61$ & $76.35 \pm 6.02$ & $78.35 \pm 7.8$ & 0.673 \\
\hline After $36 \mathrm{~h}$ & $75.5 \pm 9.25$ & $75.35 \pm 9.81$ & $79.95 \pm 10.04$ & 0.243 \\
\hline After $48 \mathrm{~h}$ & $77.35 \pm 8.49$ & $75.15 \pm 8.41$ & $77.5 \pm 13.54$ & 0.729 \\
\hline \multicolumn{5}{|l|}{ MAP } \\
\hline Baseline & $93 \pm 5.38$ & $94.05 \pm 7.09$ & $93.55 \pm 5.19$ & 0.856 \\
\hline After $2 \mathrm{~h}$ & $93.8 \pm 4.4$ & $96.3 \pm 5.37$ & $94.7 \pm 5.89$ & 0.321 \\
\hline After $4 \mathrm{~h}$ & $93.65 \pm 6$ & $93.2 \pm 6.86$ & $96.65 \pm 6.82$ & 0.205 \\
\hline After $8 \mathrm{~h}$ & $93.65 \pm 5.95$ & $92.55 \pm 7.65$ & $94.8 \pm 9.24$ & 0.657 \\
\hline After $12 \mathrm{~h}$ & $92.95 \pm 5.5$ & $93.2 \pm 4.98$ & $92.55 \pm 7.3$ & 0.942 \\
\hline After $24 \mathrm{~h}$ & $91.95 \pm 7.12$ & $91.85 \pm 5.23$ & $93.35 \pm 7.8$ & 0.739 \\
\hline After $36 \mathrm{~h}$ & $90.8 \pm 8.19$ & $90.75 \pm 8.54$ & $94.1 \pm 9.6$ & 0.392 \\
\hline After $48 \mathrm{~h}$ & $91.65 \pm 8.01$ & $90.4 \pm 8.18$ & $92.6 \pm 12.42$ & 0.775 \\
\hline
\end{tabular}


Table 3 Heart rate changes in the studied groups (bpm)

\begin{tabular}{|c|c|c|c|c|}
\hline Heart rate & Propofol group $(n=20)$ & DEX group $(n=20)$ & Mixed group $(n=20)$ & $p$ value \\
\hline Baseline & $114.15 \pm 10.16$ & $116.15 \pm 8.62$ & $117.15 \pm 13.99$ & 0.689 \\
\hline After $2 \mathrm{~h}$ & $109.55 \pm 10.36$ & $106.15 \pm 8.62$ & $107.15 \pm 13.99$ & 0.618 \\
\hline After $4 \mathrm{~h}$ & $104.35 \pm 10.64$ & $101.85 \pm 8.7$ & $101.8 \pm 14.22$ & 0.723 \\
\hline After $8 \mathrm{~h}$ & $105.1 \pm 10.94$ & $96.55 \pm 8.47^{*}$ & $97.15 \pm 13.98^{*}$ & $0.035^{*}$ \\
\hline After $12 \mathrm{~h}$ & $103.85 \pm 13.79$ & $97.25 \pm 11.67$ & $97.45 \pm 15.85$ & 0.240 \\
\hline After $24 \mathrm{~h}$ & $95.1 \pm 15.53$ & $98.5 \pm 13.3$ & $101.05 \pm 16.54$ & 0.466 \\
\hline After $36 \mathrm{~h}$ & $95.7 \pm 15.35$ & $89.1 \pm 13.18$ & $89.9 \pm 15.85$ & 0.315 \\
\hline After $48 \mathrm{~h}$ & $95.9 \pm 15.99$ & $89.55 \pm 14.52$ & $89.65 \pm 15.57$ & 0.333 \\
\hline
\end{tabular}

${ }^{*} p$ value for these results are significant as it is less than 0.01

catheter placed by author neurosurgeon using CODMAN ${ }^{\curvearrowleft}$ MICROSENSOR ${ }^{\bullet}$ ICP Transducer. The abovementioned parameters were measured at 2, 4, 8, 12, 24, 36, and $48 \mathrm{~h}$ from admission to the ICU. Neurological assessment was done for all patients by GCS and agitation scale by modified Richmond Agitation-Sedation Score (RASS) [3].

The length of ICU and hospital stay and adverse events were recorded daily for each studied patient and defined as hypotension (systolic blood pressure [SBP] $<90 \mathrm{mmHg}$ or MAP < $65 \mathrm{mmHg}$ ), hypertension (SBP > $160 \mathrm{mmHg}$ ), bradycardia (heart rate $[\mathrm{HR}]<40 \mathrm{bpm}$ ), and tachycardia (HR $>120 \mathrm{bpm})$. Assessment of delirium was performed every $12 \mathrm{~h}$ after cessation of sedation or as needed according to the patient's condition using the confusion assessment method (CAM) for ICU.

Informed consent according to the criteria set by the local research ethics committee in our center had to be obtained in writing before surgery. If consent could not be obtained because the patient was in a coma or dysphasic, consent was obtained from relatives. Through explanation, the purpose of the study and how data will be treated with respect and confidentiality were provided to the participants.

\section{Statistical plan}

Data were statistically described in terms of range, mean \pm standard deviation $( \pm S D)$, median, frequencies (number of cases), and percentages when appropriate. Comparison of quantitative variables between studied groups was done using the one-way ANOVA test. As for the samples for comparing categorical data, chi-square $\left(\chi^{2}\right)$ test was performed. A probability value of less than 0.05 was considered relative frequencies statistically significant. All statistical calculations were done using computer programs Microsoft Excel version 7 (Microsoft Corporation, NY, USA) and SPSS 20 (Statistical Package for the Social Science; SPSS Inc., Chicago, IL, USA) statistical program for Microsoft Windows (Fig. 1).

\section{Results}

Patients' general characteristics and other admission data were summarized in (Table 1). Most of our patients were in

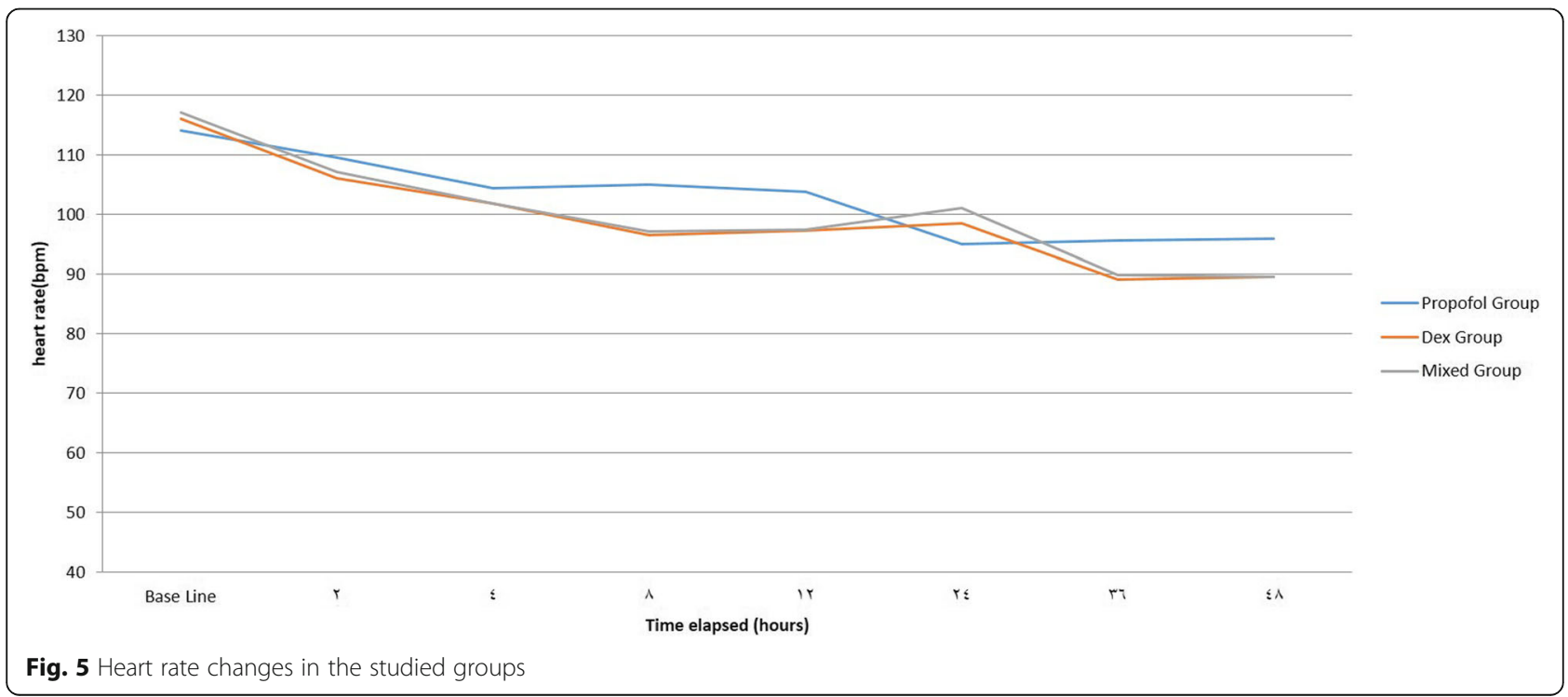


Table 4 Intracranial and cerebral perfusion pressure changes and excursions in the studied groups $(\mathrm{mmHg})$

\begin{tabular}{|c|c|c|c|c|}
\hline & $\begin{array}{l}\text { Propofol group } \\
(n=20)\end{array}$ & $\begin{array}{l}\text { DEX group } \\
(n=20)\end{array}$ & $\begin{array}{l}\text { Mixed group } \\
(n=20)\end{array}$ & $p$ value \\
\hline \multicolumn{5}{|l|}{ ICP } \\
\hline Baseline & $15.4 \pm 3.4$ & $15.7 \pm 2.9$ & $15.8 \pm 2.6$ & 0.931 \\
\hline After $2 \mathrm{~h}$ & $14.7 \pm 2.9$ & $14.4 \pm 2.8$ & $14.1 \pm 2.3$ & 0.787 \\
\hline After $4 \mathrm{~h}$ & $13.4 \pm 2.1$ & $13.7 \pm 3$ & $13.1 \pm 1.9$ & 0.703 \\
\hline After $8 \mathrm{~h}$ & $13 \pm 2.6$ & $12.6 \pm 3.5$ & $12.1 \pm 2.7$ & 0.673 \\
\hline After $12 \mathrm{~h}$ & $12.3 \pm 3.4$ & $11.9 \pm 4.2$ & $11.5 \pm 3.9$ & 0.831 \\
\hline After $24 \mathrm{~h}$ & $11.8 \pm 4.5$ & $11.1 \pm 5.5$ & $10.8 \pm 5$ & 0.811 \\
\hline After $36 \mathrm{~h}$ & $12 \pm 3.5$ & $11.6 \pm 4.4$ & $11.2 \pm 3.9$ & 0.797 \\
\hline After $48 \mathrm{~h}$ & $11.8 \pm 4$ & $11.2 \pm 4.8$ & $11 \pm 4.5$ & 0.842 \\
\hline \multicolumn{5}{|l|}{ CPP } \\
\hline Baseline & $86 \pm 5.54$ & $86.85 \pm 6.25$ & $87.3 \pm 5.41$ & 0.769 \\
\hline After $2 \mathrm{~h}$ & $89.05 \pm 4.85$ & $90.3 \pm 5.65$ & $90.75 \pm 6.93$ & 0.640 \\
\hline After $4 \mathrm{~h}$ & $89.35 \pm 4.74$ & $89.15 \pm 6.16$ & $90.95 \pm 6.13$ & 0.555 \\
\hline After $8 \mathrm{~h}$ & $89.05 \pm 6.92$ & $89.1 \pm 7.61$ & $91.35 \pm 6.93$ & 0.514 \\
\hline After $12 \mathrm{~h}$ & $89.55 \pm 5.28$ & $91.1 \pm 5.56$ & $90.8 \pm 7$ & 0.688 \\
\hline After $24 \mathrm{~h}$ & $88.75 \pm 7.74$ & $90.6 \pm 6.2$ & $91.45 \pm 7.73$ & 0.489 \\
\hline After $36 \mathrm{~h}$ & $88.1 \pm 7.59$ & $88.65 \pm 6.44$ & $90.1 \pm 9.36$ & 0.711 \\
\hline After $48 \mathrm{~h}$ & $87.65 \pm 9.73$ & $88.8 \pm 7.61$ & $90.3 \pm 10.15$ & 0.663 \\
\hline Intracranial pressure excursions, number of patients (percentage) & $6(30 \%)$ & $7(35 \%)$ & $5(25 \%)$ & 0.839 \\
\hline Cerebral perfusion pressure excursion, number of patients (percentages) & $7(35 \%)$ & $5(25 \%)$ & $2(10 \%)$ & 0.192 \\
\hline
\end{tabular}

ICP excursions $>20 \mathrm{mmHg}$. CPP excursion $<50 \mathrm{mmHg}$

the fourth decade of life; the mean age in the propofol group was $38.7 \pm 11$, in the DEX group, it was $39.3 \pm 8.5$, while it was $39.3 \pm 10.2$ in the mixed group, and there was no statistically significant difference between the means of all groups. Male patients were the majority in all groups. This finding is logical as males are more subjected to trauma due to their mobility; moreover, males are more likely than females to be involved in violent activities and motor vehicle crashes and often sustain more severe injuries compared to females.

There was no significant difference between the three studied groups at all times of the study regarding systolic, diastolic, and mean arterial blood pressure (Figs. 2, 3 , and 4) (Tables 2 and 3).

Heart rate decreased over time in all studied group in the first $48 \mathrm{~h}$. There were no significant differences between the three studied groups as regards the heart rate except after $8 \mathrm{~h}$; at this time, DEX and mixed groups showed significantly lower values compared to the propofol group (Fig. 5).

The mean baseline ICP was $15.4 \pm 3.4 \mathrm{ml}, 15.7 \pm 2.9 \mathrm{ml}$, and $15.8 \pm 2.6 \mathrm{mmHg}$ for the three studied groups respectively. These means showed no statistically significant differences with each other. ICP measurement showed no significant differences between the three groups over the $48 \mathrm{~h}$ of the study. Baseline cerebral perfusion pressure differs insignificantly between the three studied groups and continued throughout the study period over the next $48 \mathrm{~h}$. We recorded the number of ICP and CPP excursions for each patient during the infusion period and presented the median (range) per $24 \mathrm{~h}$ for each patient. The number of ICP and CPP excursions per day was also not significantly different between the three groups. When compared to each other, there was no difference in the median occurrence of ICP excursion ( $>20 \mathrm{mmHg}$ ) and CPP excursion (<50 mmHg), (Table 4) (Figs. 6 and 7).

Regarding tachycardia, bradycardia, and hypertension, there were no statistically significant differences between the three studied groups. As for hypotensive episodes, it occurred in 8 patients in the propofol group, in and 2 patients in the DEX group, and in 2 patients in the mixed group, with statistically significant differences between the three studied groups. Delirium was present in 3 out of 20 patients (15\%) in the DEX and mixed groups, while it occurred in 7 out of 20 patients $(35 \%)$ in the propofol group. There was a significant difference detected between the three studied groups regarding delirium duration. In patients in the DEX and mixed groups, 


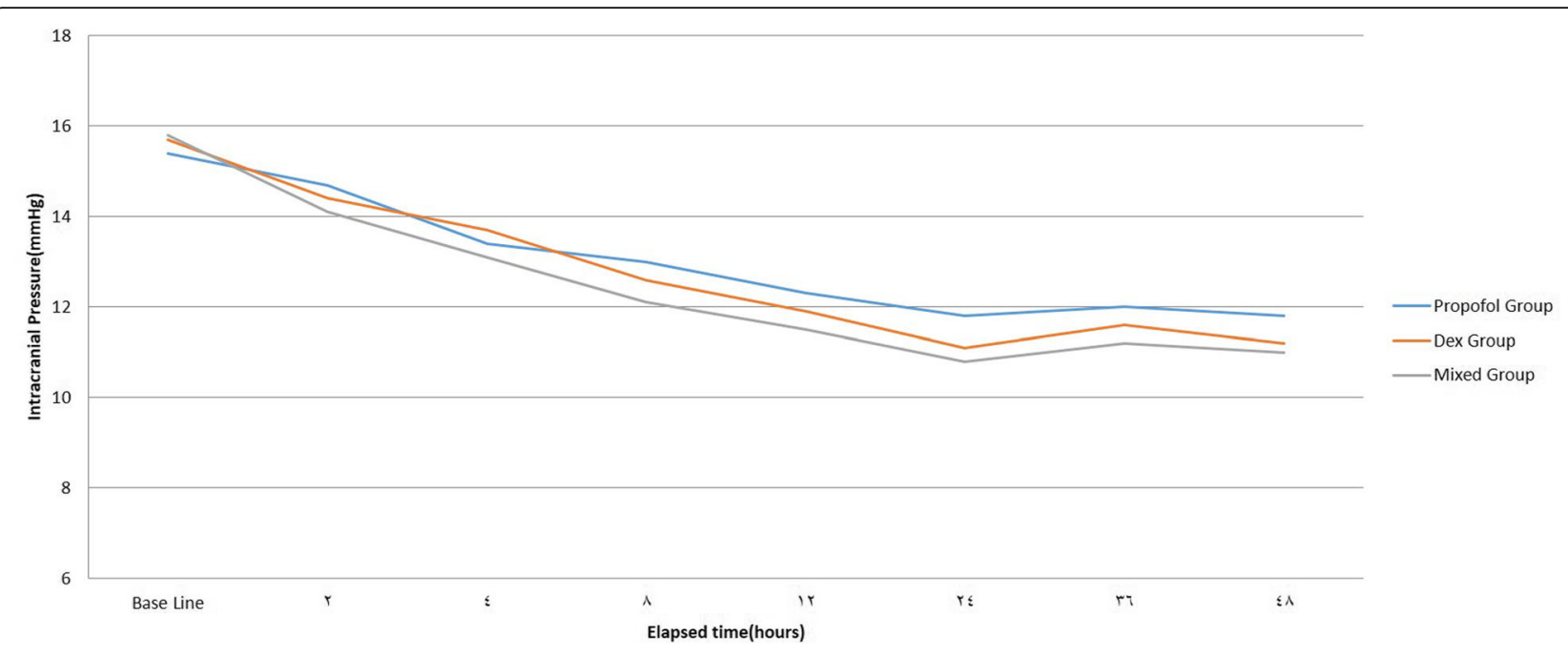

Fig. 6 Intracranial pressure changes in the studied groups

the median onset of delirium was delayed and the duration of delirium reduced, when compared to propofol group (Table 5) (Fig. 8).

\section{Discussion}

In TBI, there is a strong correlation between increased ICP and bad outcome [4-6]. The role of sedative agents in TBI extends from allowing mechanical ventilation which prevents hypoxia and hypercapnia and decreases $\mathrm{CMRO}_{2}$ and hence ICP. These beneficial effects of sedation are opposed by the fact that these sedative agents may produce harmful episodes of hemodynamic instability; hypotensive episodes may greatly affect the outcome $[8,9]$.

The results of our study showed no statistically significant differences between the three groups as regards the values of ICP and CPP, mean arterial blood pressure, or the incidence of hypertensive or bradycardic episodes between the three studied groups.

Different studies showed the favorable effect of propofol on brain hemodynamics when used as sedative agents $[7,10]$. Aryan et al. also showed that there was a slight decrease in the mean for ICP and a small corresponding increase in CPP with DEX administration in 39 neurosurgical patients. They concluded that dexmedetomidine can be a safe and effective sedative agent for neurosurgical patients [11]. Pajoumand et al., in their study, found that DEX failed to decrease the maximum ICP in the first and second day of the trauma compared to propofol or a mixture of DEX and propofol. DEX reached its maximum effect on reduction of ICP on day 4 after the trauma. Moreover, it was

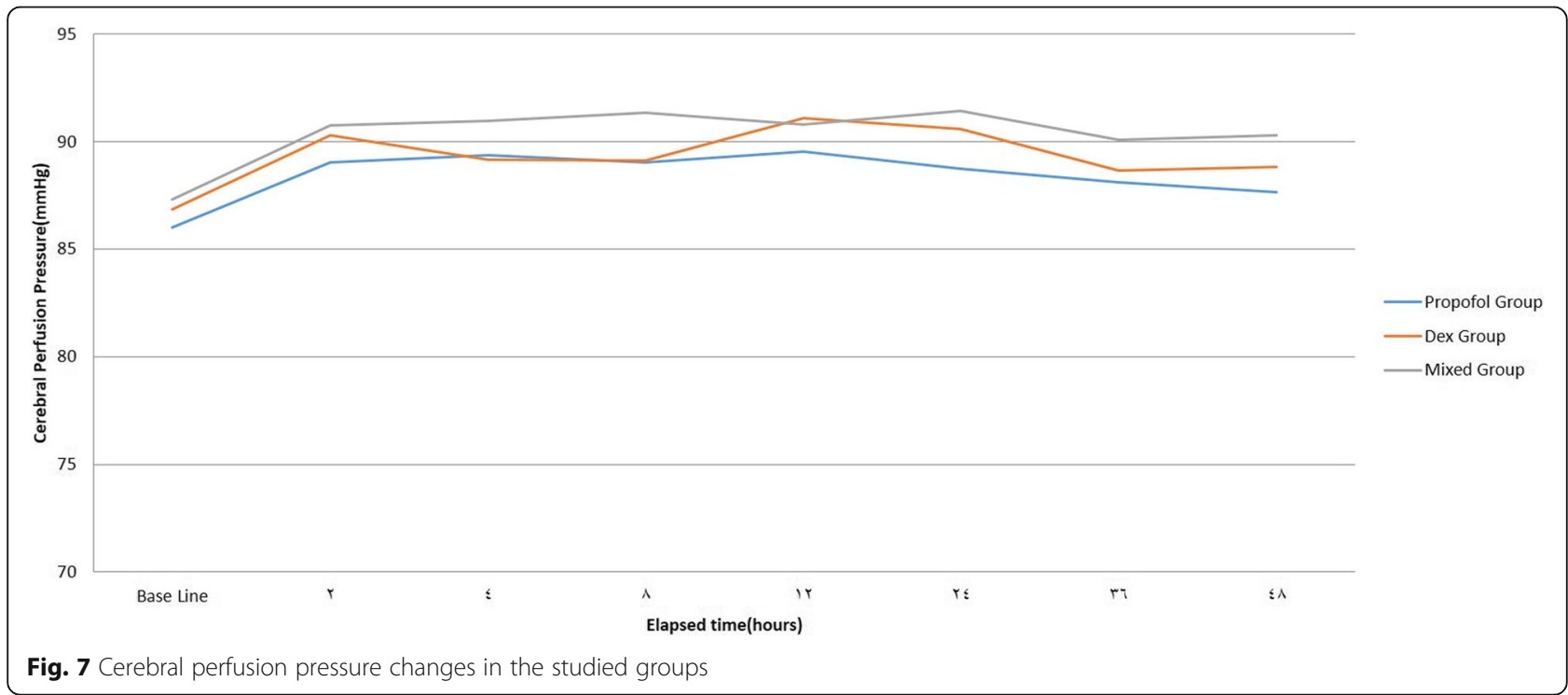


Table 5 Clinical outcome, length of stay, complications, and delirium in the studied groups

\begin{tabular}{|c|c|c|c|c|}
\hline & $\begin{array}{l}\text { Propofol group } \\
(n=20)\end{array}$ & $\begin{array}{l}\text { DEX group } \\
(n=20)\end{array}$ & $\begin{array}{l}\text { Mixed group } \\
(n=20)\end{array}$ & $p$ value \\
\hline $\begin{array}{l}\text { GCS on discharge } \\
\text { from ICU, median (range) }\end{array}$ & $12(8.75)$ & $12(7.5)$ & $12(5.75)$ & 0.604 \\
\hline $\begin{array}{l}\text { Length of ICU } \\
\text { stay (days) }\end{array}$ & $23.5 \pm 3$ & $24.1 \pm 2.8$ & $22.9 \pm 3.1$ & 0.428 \\
\hline $\begin{array}{l}\text { Length of hospital } \\
\text { stay (days) }\end{array}$ & $46.6 \pm 3.8$ & $48 \pm 3.1$ & $46.4 \pm 4.2$ & 0.329 \\
\hline \multicolumn{5}{|l|}{ Complications } \\
\hline Bradycardia & $3(15 \%)$ & $6(30 \%)$ & $3(15 \%)$ & 0.392 \\
\hline Tachycardia & $7(35 \%)$ & $5(25 \%)$ & $2(10 \%)$ & 0.170 \\
\hline Hypotension & $8(40 \%)$ & $2(10 \%)$ & $2(10 \%)$ & $0.024^{*}$ \\
\hline Hypertension & $6(30 \%)$ & $6(30 \%)$ & $4(20 \%)$ & 0.711 \\
\hline Vomiting & $5(25 \%)$ & $3(15 \%)$ & $1(5 \%)$ & 0.208 \\
\hline $\begin{array}{l}\text { Patients needed } \\
\text { mechanical ventilation }\end{array}$ & $4(20 \%)$ & $2(10 \%)$ & $1(5 \%)$ & 0.322 \\
\hline $\begin{array}{l}\text { Death rate till } \\
\text { ICU discharge }\end{array}$ & $2(10 \%)$ & $1(5 \%)$ & $1(5 \%)$ & 0.765 \\
\hline \multicolumn{5}{|l|}{ Delirium } \\
\hline Incidence & $7(35 \%)$ & $3(15 \%)$ & $3(15 \%)$ & 0.208 \\
\hline Onset (days) & $2(1-5)$ & $1(2-4)$ & $2(2-4)$ & 0.138 \\
\hline Duration (days) & $3(1-4)$ & $2(1-3)$ & $2(1-4)$ & $0.034^{*}$ \\
\hline
\end{tabular}

${ }^{*} p$ value for these results are significant as it is less than 0.01

significantly lesser in the DEX group compared to propofol or DEX-propofol mixture [12].

A recent retrospective cohort study conducted by Schomer et al. concluded that dexmedetomidine may avoid increases in the need for rescue therapy when used as an adjunctive treatment of refractory intracranial hypertension without compromising hemodynamics [13]. Also, Erdman et al. in their retrospective multicenter trial compared the hemodynamic effects of DEX and propofol in neurocritical patients; they found a similar incidence of hypotension between DEX and propofol and they recommended more trial on patients with TBI only [14].

Devabhakthuni et al. compared the safety and clinical outcomes of prolonged infusions with standard-dose $(\leq 0.7 \mu \mathrm{g} / \mathrm{kg} / \mathrm{h})$ dexmedetomidine (SDD) or high-dose $(>0.7 \mu \mathrm{g} / \mathrm{kg} / \mathrm{h}$ ) dexmedetomidine (HDD) to propofol in critically ill trauma patients. They concluded that higher doses of dexmedetomidine may result in higher

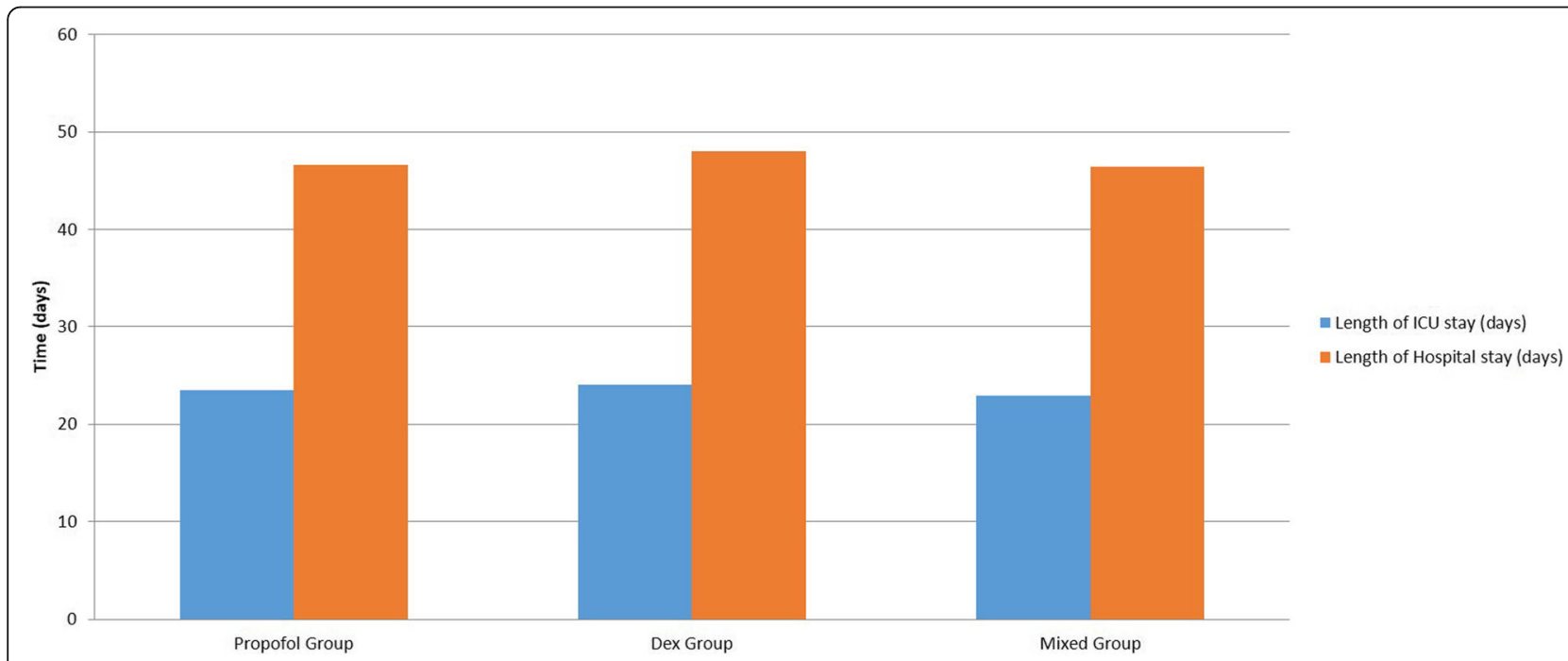

Fig. 8 Length of ICU and hospital stay in the studied groups 
incidence of hypotension, longer LOS, and increased concomitant analgesic and sedative, requiring further evaluation in trauma patients [8].

Hypertension may also complicate critically ill head trauma patients. This may be due to inadequate sedation or due to paroxysmal sympathetic hyperactivity associated with head trauma. In our study, we find no differences in the incidence of hypertension between the three studied groups. Riker et al., in their double-blinded prospective study, found that patients sedated with DEX compared to midazolam have lesser ventilation hours and decreased incidence of hypertension and tachycardia [15]. Authors proposed that sympatholytic activity of DEX may be adventitious in the alleviation of these symptoms $[9,15-19]$.

In our study, we observed higher although non-significant increase in the incidence of delirium in the propofol group compared to other two groups. The only significant difference was observed in the duration of delirium which was longer on propofol compared to other groups. Djaiani et al. concluded that, when compared with propofol, dexmedetomidine sedation reduced the incidence, delayed the onset, and shortened the duration of delirium in ICU patients [20].

Propofol has been associated with rapid regain of consciousness upon discontinuation of sedation and better quality of sedation. Tang et al., in their study of nonintubated TBI patients, also showed that DEX allowed clinicians to conduct periodic neurologic examinations $[17,2]$. Clinicians use propofol more commonly as the sedative for patients with TBI due to its extensively described neuroprotective effects [21, 22].

Limitations of our study may include the lack of generalizability as this is a single center study. We did not study the period after discontinuation of both sedative agent, and we did not study the opioid needs and opioid-sparing effect of both agents. We also evaluated the sedation level of patients by loss of agitation and being calm not by any scores like Richmond Agitation-Sedation Score (RASS).

\section{Conclusion}

From this study, we conclude that dexmedetomidine or combination of dexmedetomidine and propofol are as effective and safe as propofol alone in head trauma patients, and all alternatives are equal as regards the degree of sedation, the effect on intracranial pressure, and cerebral perfusion pressure. The incidence of complications and outcome do not vary significantly between all studied groups; although there are some results suggesting that dexmedetomidine might have better results regarding delirium "onset and duration", these findings need a larger sample size study. Therefore, although larger series are needed to confirm our results, we found that dexmedetomidine is an option to be taken into account in the integral management of patients with TBI.

\section{Acknowledgements}

Not applicable.

Funding

Not applicable.

Availability of data and materials

All data generated or analyzed during this study are included in this published article.

\section{Authors' contributions}

MK is the main author who contributed to the study design and analysis of patients' data and is responsible for the neurosurgical procedure and writing of the publication. AM contributed to the data collection and followed up the patients at the ICU. MA, ES, and SA-r contributed to the analysis of the patients' data. All authors read and approved the final manuscript.

\section{Ethics approval and consent to participate}

Research committee approval has been granted for this study by the Medical Ethics Committee, Faculty of Medicine, Assiut University. with ethics committee approval number 17200257 on May 2013. Informed consent according to the criteria set by the local research ethics committee in our centre had to be obtained in writing before surgery. If consent could not be obtained because the patient was in coma or dysphasic consent was obtained from relatives. Through explanation to the purpose of the study and how data will be treated with respect and confidentiality was provided to the participants.

Consent for publication

Not applicable.

\section{Competing interests}

The authors declare that they have no competing interests.

\section{Publisher's Note}

Springer Nature remains neutral with regard to jurisdictional claims in published maps and institutional affiliations.

\section{Author details}

${ }^{1}$ Department of Neurosurgery, Assiut University Hospital, Assiut, Egypt. 2Department of Anesthesia and Intensive Care, Assiut University Hospital, Assiut, Egypt.

Received: 11 October 2018 Accepted: 18 March 2019 Published online: 04 April 2019

\section{References}

1. Singh A, Sharma P, Mishra S. Neuro-protection after traumatic brain injury: novel strategies. J Dent Med Sci. 2013;3(6):75-85.

2. Smith M. Monitoring intracranial pressure in traumatic brain injury. Anesth Analg. 2008;106(1):240-8.

3. Marmarou A, Anderson RL, Ward JD, Choi SC, Young HF, Eisenberg HM, et al. Impact of ICP instability and hypotension on outcome in patients with severe head trauma. Special Supplements. 1991;75(1S):S59-66.

4. Marmarou A. Increased intracranial pressure in head injury and influence of blood volume. J Neurotrauma. 1992;9:S327-32.

5. Roberts DJ, Hall Rl, Kramer AH, Robertson HL, Gallagher CN, Zygun DA. Sedation for critically ill adults with severe traumatic brain injury: a systematic review of randomized controlled trials. Crit Care Med. 2011; 39(12):2743-51.

6. Strebel S, Lam A, Matta B, Mayberg TS, Aaslid R, Newell DW. Dynamic and static cerebral autoregulation during isoflurane, desflurane, and propofol anesthesia. The Journal of the American Society of Anesthesiologists. 1995; 83(1):66-7.

7. Chrysostomou C, Schmitt CG. Dexmedetomidine: sedation, analgesia and beyond. Expert Opinion Drug Metabolism Toxicology. 2008;4:61927. 
8. Chesnut RM, Marshall LF, Klauber MR, Blunt BA, Baldwin N, Eisenberg HM, et al. The role of secondary brain injury in determining outcome from severe head injury. J Trauma. 1993;34(2):216-22.

9. Fearnside MR, Cook RJ, McDougall P, McNeil RJ. The Westmead Head Injury Project outcome in severe head injury. A comparative analysis of prehospital, clinical and CT variables. Br J Neurosurg. 1993;7(3):267-79.

10. Miller JD, Butterworth JF, Gudeman SK, Faulkner JE, Choi SC, Selhorst JB, et al. Further experience in the management of severe head injury. $J$ Neurosurg. 1981;54(3):289-99.

11. Aryan HE, Box KW, Ibrahim D, Desiraju U, Ames CP. Safety and efficacy of dexmedetomidine in neurosurgical patients. Brain Inj. 2006;20(8):791-8.

12. Pajoumand M, Kufera JA, Bonds BW, Devabhakthuni S, Boswell S, Hesselton $\mathrm{K}$, et al. Dexmedetomidine as an adjunct for sedation in patients with traumatic brain injury. The journal of trauma and acute care surgery. 2016.

13. Narayan RK, Greenberg RP, Miller JD, Enas GG, Choi SC, Kishore PR, et al. Improved confidence of outcome prediction in severe head injury: a comparative analysis of the clinical examination, multimodality evoked potentials, CT scanning, and intracranial pressure. J Neurosurg. 1981;54(6):751-62

14. Erdman MJ, Doepker BA, Gerlach AT, Phillips GS, Elijovich L, Jones GM. A comparison of severe hemodynamic disturbances between dexmedetomidine and propofol for sedation in neurocritical care patients. Crit Care Med. 2014;42(7):1696-702.

15. Riker RR, Shehabi Y, Bokesch PM, Ceraso D, Wisemandle W, Koura F, et al. Dexmedetomidine vs midazolam for sedation of critically ill patients: a randomized trial. Jama. 2009:301(5):489-99.

16. Farling P, Johnston J, Coppel D. Propofol infusion for sedation of patients with head injury in intensive care. Anaesthesia. 1989:44(3):222-6.

17. Ronan KP, Gallagher TJ, George B, Hamby B. Comparison of propofol and midazolam for sedation in intensive care unit patients. Crit Care Med. 1995;23(2):286-93.

18. MCKeage K, Perry CM. Propofol. CNS drugs. 2003;17(4):235-72.

19. Wang $X$, Ji J, Fen L, Wang A. Effects of dexmedetomidine on cerebral blood flow in critically ill patients with or without traumatic brain injury: a prospective controlled trial. Brain Inj. 2013;27(13-14):1617-22.

20. Djaiani G, Silverton N, Fedorko L, Carroll J, Styra R, Rao V, et al. Dexmedetomidine versus propofol sedation reduces delirium after cardiac surgery: a randomized controlled trial. The Journal of the American Society of Anesthesiologists. 2016;124(2):362-8.

21. Rossaint J, Rossaint R, Weis J, Fries M, Rex S, Coburn M. Propofol: neuroprotection in an in vitro mode of traumatic brain injury. Crit Care. 2009;13:R61.

22. Tanguy $M$, Seguin $P$, Laviolle B, Bleichner J-P, Morandi $X$, Malledant $Y$. Cerebral microdialysis effects of propofol versus midazolam in severe traumatic brain injury. J Neurotrauma. 2012;29(6):1105-10.

\section{Submit your manuscript to a SpringerOpen ${ }^{\circ}$ journal and benefit from:}

- Convenient online submission

- Rigorous peer review

- Open access: articles freely available online

High visibility within the field

- Retaining the copyright to your article

Submit your next manuscript at $\boldsymbol{\nabla}$ springeropen.com 